\title{
Hemocyte proteome of the Lake Baikal endemic Eulimnogammarus verrucosus (Crustacea: Amphipoda) sheds light on immune-related proteins
}

\author{
Elena Zolotovskaya ${ }^{1}$, Anna Nazarova ${ }^{1}$, Alexandra Saranchina ${ }^{1}$, \\ Andrei Mutin ${ }^{1}$, Polina Drozdova ${ }^{1,2}$, Yulia Lubyaga ${ }^{1,2}$, and \\ Maxim Timofeyev ${ }^{1,2}$ \\ ${ }^{1}$ Irkutsk State University, ul. Karla Marksa, 1, Irkutsk, 664003, Russian Federation \\ ${ }^{2}$ Baikal Research Centre, ul. Lenina, 21, Irkutsk, 664003, Russian Federation \\ Address correspondence and requests for materials to Maxim Timofeyev, \\ m.a.timofeyev@gmail.com
}

Citation: Zolotovskaya, E., Nazarova, A., Saranchina, A., Mutin, A., Drozdova, P., Lubyaga, Yu., and Timofeyev, M. 2021. Hemocyte proteome of the Lake Baikal endemic Eulimnogammarus verrucosus (Crustacea: Amphipoda) sheds light on immune-related proteins. Bio. Comm. 66(4): 290-301. https://doi.org/10.21638/ spbu03.2021.402

Authors' information: Elena Zolotovskaya, Junior Researcher, orcid.org/00000003-2753-4224; Anna Nazarova, Junior Researcher, orcid.org/0000-0002-5388-2559; Alexandra Saranchina, Researcher, orcid. org/0000-0002-5756-1525; Andrei Mutin, Junior Researcher, orcid.org/0000-00023092-5376; Polina Drozdova, PhD, Leading Researcher, orcid.org/0000-0003-3955-6105; Yulia Lubyaga, PhD, Leading Researcher, orcid.org/0000-0002-2494-8723; Maxim Timofeyev, Dr. of Sci. in Biology, Professor, Director of Institute, orcid.org/0000-00025250-6818

Manuscript Editor: Anton Nizhnikov, Department of Genetics and Biotechnology, Faculty of Biology, Saint Petersburg State University, Saint Petersburg, Russia

Received: February 18, 2021;

Revised: May 15, 2021

Accepted: May 26, 2021.

Copyright: ( 2021 Zolotovskaya et al. This is an open-access article distributed under the terms of the License Agreement with Saint Petersburg State University, which permits to the authors unrestricted distribution, and self-archiving free of charge.

Funding: The reported study was funded by RFBR and the Government of the Irkutsk Region, project number 20-44-383007.

Ethics statement: The studied species are highly abundant and not endangered or protected. All applicable international, national, and institutional guidelines for the care and use of animals were followed. The research was approved by the Animal Subjects Research Committee of the Institute of Biology at Irkutsk State University (ASRC Protocol No. 2018-3).

Supplementary information:

Supplemental material to the article is available at https://doi.org/10.21638/ spbu03.2021.402. Supplementary files are published as submitted by the authors, and are not copyedited.

Competing interests: The authors have declared that no competing interests exist.

\begin{abstract}
Hemocytes are cells circulating in the hemolymph and playing an important role in crustacean immunity. These cells not only function as phagocytes but also express immune compounds to the hemolymph. Here we obtained hemocyte proteome of the endemic amphipod (Amphipoda, Crustacea) Eulimnogammarus verrucosus from Lake Baikal, the first hemocyte proteome of an amphipod, using liquid chromatography/tandem mass spectrometry (LC-MS/MS). A total of 1152 unique proteins were discovered with LC-MS/MS. We discovered both proteins directly involved in the immune response, such as pattern recognition proteins (C-type lectins), and compounds with antimicrobial activity (ctenidin and anti-lipopolysaccharide factor/scygonadin). Moreover, hemocyanins which may act as a phenoloxidase and C-type lectins were among the most diverse protein groups in the hemocyte proteome. The obtained data can be useful for further studies of immune components and mechanisms in Baikal amphipods.
\end{abstract}

Keywords: hemocytes, LC-MS/MS, proteome, Lake Baikal, crustacean, amphipod, innate immunity, antimicrobial peptide, lectin

\section{Introduction}

Crustaceans are a species-rich and diverse group of the phylum Arthropoda, represented by a large number of species inhabiting both aquatic and terrestrial environments. The members of this group play a significant role in the planetary ecosystem and also in aquaculture (Watling and Thiel, 2013). In aquatic ecosystems crustaceans participate in food webs, acting as a food source for fish, and play a role as detritivores, contributing to the removal of organic debris. In aquaculture crustaceans are among the most important objects and an essential source of aquatic food protein (Bondad-Reantaso et al., 2012).

An important aspect in any natural or artificial ecosystem is protection against pathogen or parasite invasion, which is ensured by the immune system. The immunity status can influence the efficiency of aquaculture production, and it also affects the resistance of invertebrates to a variety of stressors in natural ecosystems. However, functioning of the immune system is still an understudied topic in the physiology of aquatic invertebrates.

Crustaceans, like most invertebrates, possess innate immunity. In the internal environments of crustaceans, the immune response is mostly executed by hemocytes (cellular immunity) and effector molecules circulating in hemolymph plasma (humoral immunity). (Cerenius, Jiravanichpaisal, Liu and Soderhall, 2010). These components are closely connected to each other; e.g., compounds 
involved in the humoral immune response can be synthesized and secreted by hemocytes in response to a foreign body.

Defense against pathogens in crustaceans depends on various pattern recognition proteins (PRPs), which are molecular receptors that circulate in hemolymph plasma or are carried on the hemocyte surface. The function of these receptors is to recognize pathogenassociated molecular patterns (PAMPs) and activate signaling cascades, as well as cellular and humoral mechanisms necessary to eliminate pathogens (Mydlarz, Jones and Harvell, 2006). PRPs are one of the most important building blocks of innate immunity since foreign object recognition is the starting point of the immune response.

Pathogen recognition activates various defense mechanisms. Some of them are involved in the humoral immune response, including the activation of the phenoloxidase cascade leading to melanin formation. PAMPs also activate hemocytes by interacting with PRPs on the cellular surface. Depending on the nature of the foreign object, hemocytes perform different immune functions (Chang and Thiel, 2015). These cells engulf or encapsulate foreign objects and can also secrete some components of humoral immunity into the hemolymph. Mostly (but not always) crustaceans are reported to have three types of hemocytes. These types are plasmocytes (hyalinocytes), semigranulocytes (small granulocytes) and granulocytes. These morphological features reflect their different functions like encapsulation (plasmocytes) or phagocytosis (plasmocytes and semigranulocytes) of foreign objects; degranulation and activation of the melanization process including activation of the phenoloxidase cascade (semigranulocytes, granulocytes); and also antimicrobial peptide synthesis (granulocytes) (Rowley, 2016). However, the molecular processes behind these functions are largely unstudied.

Amphipods are a large order of crustaceans that play an important role in aquatic ecosystems around the world, including in continental waters. One impressive hotspot of amphipod speciation is Lake Baikal; to date, more than 350 species and subspecies are known in this ancient lake (Sket, Morino, Takhteev and Rogers, 2019). Baikal amphipods are characterized by the high diversity of their ecological niches, which leads to a variety of physiological characteristics (Axenov-Gribanov et al., 2016; Drozdova et al., 2019). Reported parasites of Baikal amphipods include microsporidia (Madyarova et al., 2015; Dimova et al., 2018; Ironside and Wilkinson, 2018), acanthocephalans (Amin et al., 2015) and leeches (Kaygorodova and Natyaganova, 2012); in addition, symbiotic bacteria are also found (Protasov et al., 2017).

However, there is no information on the functional diversity of the immune system that could evolve during evolutionary specialization of Baikal amphipods to various habitats and conditions within the lake. The only available study on functional properties of immune response of a Baikal amphipod demonstrated a pronounced reaction of hemocytes to foreign bodies in the primary culture in vitro without the humoral factors of hemolymph (Shchapova et al., 2019). This observation directly indicates the presence of PRPs in the membranes of amphipod hemocytes and highlights the role of these cells in initiation of the immune response.

Thus, our research was aimed at obtaining data about hemocyte protein composition of the Baikal endemic amphipod Eulimnogammarus verrucosus (Gerstfeldt, 1858) (Fig. 1A) to obtain the first insight into the molecular mechanisms of immunity in Baikal amphipods. This species of amphipods inhabits the littoral part of the lake and is widespread throughout Lake Baikal, being a dominant species in the littoral communities (Kravtsova et al., 2004); in addition, it has a relatively large size in comparison with other littoral amphipods. In this work, we characterized the hemocyte proteome of E. verrucosus by liquid chromatography-mass spectrometry (LC-MS/MS).

\section{Materials and methods}

\section{Experimental animals}

The species of Baikal endemic amphipod Eulimnogammarus verrucosus (Gerstfeldt, 1858) is a typical inhabitant of littoral communities in Lake Baikal (Fig. 1A). These crustaceans are widespread in the lake and live under stones at depths from a few centimeters to 15 meters. Adult individuals have a body size of about $2-4 \mathrm{~cm}$ (Bazikalova, 1945). This species is phytophagous (Kamaltynov, 1999). These crustaceans are stenothermal and cold-loving; reproduction occurs at $0-6^{\circ} \mathrm{C}$. The first females with eggs appear in the second half of October. The massive exit of young crustaceans begins in the end of May and finishes in the second half of July. The species has a high growth rate and reaches a significant size in the first year, reaching maturity in the second year. Lifespan is over two years (Bazikalova, 1945). Various literature sources report parasites, such as microsporidia belonging to the Enterocytospora-like clade (Madyarova et al., 2015) and the genus Nosema (Dimova et al., 2018), acanthocephalans of the Echinorhynchidae family (Amin et al., 2015), and leeches of the species Baicalobdella torquata (Kaygorodova and Natyaganova, 2012) in Baikal amphipods E. verrucosus. Besides, symbiotic bacteria are present in various amphipods (Protasov et al., 2017), but their role in host-symbiont relationships is still unclear.

The amphipods were collected with a hand net in the littoral zone of Lake Baikal near the bay in Listvyanka $\left(51^{\circ} 52^{\prime} 05.5^{\prime} \mathrm{N} 104^{\circ} 49^{\prime} 47.1^{\prime} \mathrm{E}\right)$. The amphipods were caught in July 2020. After sampling, the animals were 

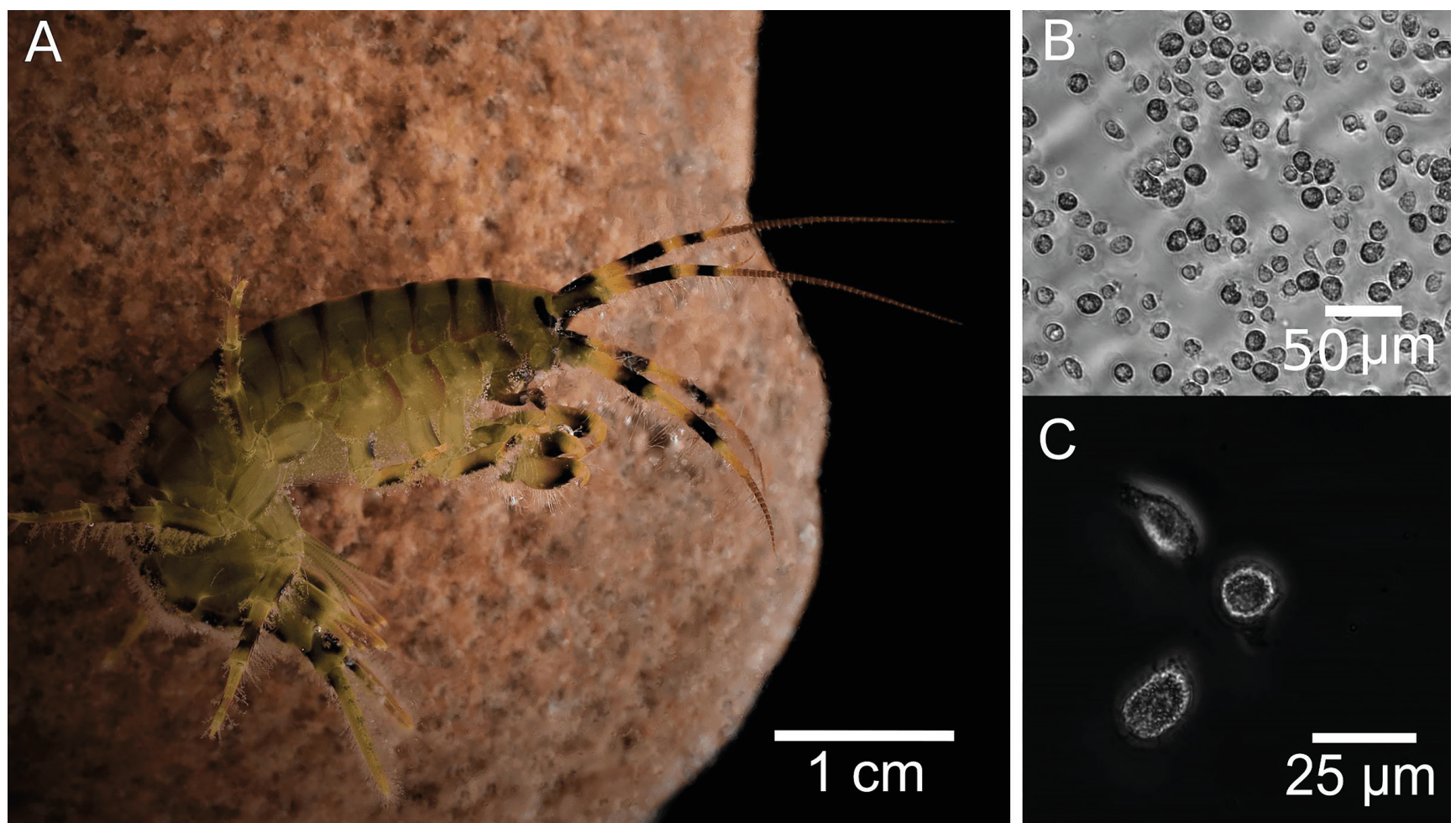

Fig. 1. Representative photo of the research object and its hemocytes. (A) Photo of amphipod E. verrucosus. Photo by K. Vereshchagina. (B) Hemocytes in the brightfield channel mixed 1:1 with anticoagulant solution in 96-well plate and (C) in phase contrast.

transferred to the laboratory. The acclimation of amphipods was carried out for 3-4 days at the temperature of $6-10^{\circ} \mathrm{C}$ in well-aerated $2.5 \mathrm{~L}$ aquaria with Baikal water. The temperature of acclimation matches the average annual temperature of the Baikal littoral zone. The water was changed every 2 days. The amphipods were fed with a dried and ground mixture of algae and macroinvertebrates from their habitat.

\section{Hemolymph collection and hemocyte isolation}

For hemolymph sampling, we used adult individuals of E. verrucosus with body size from $2.5 \mathrm{~cm}$. The hemolymph volume of these individuals was at least $70 \mu \mathrm{L}$. Before extraction, we sterilized the dorsal side of the pereon with $70 \%$ ethanol. The hemolymph was collected from the central blood vessel between the $6^{\text {th }}$ and $7^{\text {th }}$ mesosome segments using a sterile glass capillary.

We used 18-20 amphipods (containing at least $70 \mu \mathrm{L}$ of hemolymph per animal) to obtain one sample. The sampled hemolymph was mixed on ice with an anticoagulant solution ( $150 \mathrm{mM} \mathrm{NaCl}, 5 \mathrm{mM} \mathrm{Na}_{2} \mathrm{HPO}_{4}, 10 \mathrm{mM}$ EDTA, $30 \mathrm{mM}$ sodium citrate, $\mathrm{pH} 8.0$ ) in a 1:1 ratio (Shchapova et al., 2019). The cell mixture was centrifuged to separate cells from the hemolymph plasma ( $100 \mathrm{~g}$ for $5 \mathrm{~min}$ at $4^{\circ} \mathrm{C}$ ) (George and Dhar, 2010). Half of the upper fraction with hemolymph plasma was discarded, and the cell pellet was mixed with a buffer solution $(150 \mathrm{mM}$
$\mathrm{NaCl}, 5 \mathrm{mM} \mathrm{Na}_{2} \mathrm{HPO}_{4}$, pH 8.0). The samples with hemocytes were centrifuged twice under the same conditions for complete hemolymph plasma removal. The supernatant was discarded carefully, and the pure hemocyte fraction mixed with a small amount of buffer was stored at $-80^{\circ} \mathrm{C}$. Thus, two samples of purified hemocytes were obtained for protein isolation in different ways.

Hemocytes were visualized in hemolymph mixed 1:1 with the anticoagulant solution in a 96-well plate using a Celena S Digital imaging system (Logos Biosystems, South Korea) in brightfield with a $10 \times$ objective (Fig. 1B) and in phase contrast with a $40 \times$ objective (Fig. 1C).

\section{Protein extraction from hemocytes}

Protein isolation was performed as described by Bedulina et al. (2016) with some modifications. We added $20 \%$ phenylmethylsulfonyl fluoride (PMSF) to the purified hemocyte fraction in the final concentration of $1 \%$ of the sample volume. Protein purification buffer (0.1 M Tris$\mathrm{HCl}, \mathrm{pH} 7.6,1 \%$ protease inhibitor cocktail) was added to the sample further in a 1:1 ratio. For more efficient isolation of hemocyte membrane proteins, $0.2 \%$ sodium dodecyl sulfate (SDS) was added to one of two samples. The mixture was centrifuged ( $6058 \mathrm{~g}$ for $15 \mathrm{~min}$ at $4^{\circ} \mathrm{C}$ ) to remove cell debris. Protein concentration in the samples was measured with the Bradford procedure (Bradford, 1976). The samples with at least $100 \mathrm{mg}$ of protein were mixed with $10 \%$ trichloroacetic acid and centrifuged 
(14171 $\mathrm{g}$ for $15 \mathrm{~min}$ at $4{ }^{\circ} \mathrm{C}$ ) to precipitate the proteins. The pellet was washed twice with cold $80 \%$ ethanol. Pure hemocyte protein was resuspended in the protein purification buffer, mixed with cold acetone, and incubated for $30 \mathrm{~min}$ at $-24^{\circ} \mathrm{C}$. The samples were dried at room temperature. This dry pellet was directly shipped for LC-MS/MS analysis. Thus, two samples containing hemocyte proteins with and without the addition of SDS were obtained.

\section{Mass spectrometry and data analysis}

Proteomic analysis of E.verrucosus hemocyte proteins was performed at the Advanced Mass Spectrometry Core Facility (Skoltech, Moscow). Preparation of the two obtained samples (with and without SDS) included protein digestion with trypsin, ZipTip desalting, and LC-MS/ MS analysis in three analytical repeats (gradient up to $120 \mathrm{~min}$ ) with a Q Exactive Orbitrap mass-spectrometer (Thermo Fisher Scientific, USA). Data analysis was carried out using SearchGUI v3.3.17 and Peptide Shaker v1.16.44 software (Vaudel, Burkhart and Zahedi, 2015). The mass spectrometry proteomics data have been deposited to the ProteomeXchange Consortium via the PRIDE (Perez-Riverol, et al. 2019) partner repository with the dataset identifier PXD023514 and 10.6019/PXD023514.

Protein identification was conducted using a database, which consisted of the proteins predicted in the E. verrucosus transcriptome assembly GHHK01 (Drozdova et al., 2019) predicted with TransDecoder v5.5.0 (Haas et al., 2013) and protein contaminants database CRAP (ftp://ftp.thegpm.org/fasta/cRAP; version of March 4, 2019). Peptide search was performed with the following options: trypsin as the digesting enzyme, precursor $\mathrm{m} / \mathrm{z}$ tolerance $10.0 \mathrm{ppm}$; fragment $\mathrm{m} / \mathrm{z}$ tolerance $0.5 \mathrm{Da}$; two missed cleavage sites possible, false-positive frequency of occurrence for peptides and proteins less than $1 \%$. Cysteine carbamidomethylation (carbamidomethylation of C) and methionine oxidation (oxidation of $\mathrm{M}$ ) were set as fixed and variable modifications, respectively. Transcript annotation in assembly was carried out with the diamond algorithm v0.9.23.124 (Buchfink, Xie and Huson, 2014) and nr database from March 20, 2020.

The SignalP-5.0 server and standalone versions (Armenteros et al., 2019) were used to predict and trim signal sequences. The presence of transmembrane domains was analysed with TMHMM (Krogh, Larsson, Von Heijne and Sonnhammer, 2001) v2.0. TreeGrafter (Tang, Finn and Thomas, 2019) v1.01 was used to annotate the found proteins with the Panther (Mi et al., 2019) protein classes, while the eggNOG-mapper v2 was employed for the functional annotation of the protein sequences with Gene Ontology (GO) terms, Kyoto Encyclopedia of Genes and Genomes (KEGG) pathways, and clusters of orthologous groups (COGs) using eggNOG v5.0 clusters and phylogenies (Huerta-Cepas et al., 2017, 2019).
The results of protein identification were united with the R software (R Development Core Team, 2019) using the seqinr (Charif and Lobry, 2007) package and visualized with ggplot2 (Wickham, 2016). Reproducible code for data analysis is available from https://git.io/JLh5C.

\section{Results}

To provide the first characteristic of the hemocyte proteome of E. verrucosus, we analyzed two proteome samples with LC-MS/MS. One of the samples was prepared with $0.2 \%$ SDS in the extraction buffer, while in the other SDS was not added. This detergent may increase the extraction efficiency of membrane proteins, but at the same time may interfere with mass spectrometry identification (Sun, Wang and Li, 2012). Each sample was analyzed in three technical replicates.

The overall count of identified proteins ranged from 697 to 878 per sample; 1152 proteins were identified in at least one replicate, and 431 proteins were identified in all six replicates (Fig. 2A; Table S1). The number of proteins with predicted transmembrane domains was about two times higher in the sample extracted with SDS (78-81 vs. $38-41$ ). The total number of identified proteins was also higher in the SDS-containing sample. Figure 2B shows the overlap of the protein sequence set between three technical repeats in the sample with the addition of SDS and without the addition of SDS. In samples with SDS and without SDS, 609 and 584 protein sequences were found, which were identified in each of the three repeats. Of all proteins identified in at least one replicate, $731(63.5 \%)$ were found both in the sample with SDS and in the sample without it (Fig. 2C); 472 proteins were found in SDS and SDS-free samples, which amounts to $65.5 \%$ of all proteins consistently identified in three technical replicates (Fig. 2D).

To represent the diversity of proteins in the resulting hemocyte proteome, we annotated the found proteins according to the Panther database. Figure 2E shows the 15 Panther families, to each of which at least five identified proteins were assigned. These families were found in hemocyte proteome in the greatest amounts.

First, we analyzed the diversity of protein families within SDS-specific proteins (i.e., those found only in the sample with SDS). A total of 290 SDS-specific proteins were found. Among the proteins found in the SDStreated sample, there were sequences belonging to the families of both immune and non-immune proteins, according to the Panther database annotation. The number of sequences annotated in this database was about $74 \%$ of all proteins found in the sample with SDS. We found some sequences from the protein families most represented in hemocyte proteome (Fig. 2E). There were two sequences belonging to the superfamily of C-type lectins, and none of them contained a transmembrane domain. Three proteins belonged to the actin family, while 


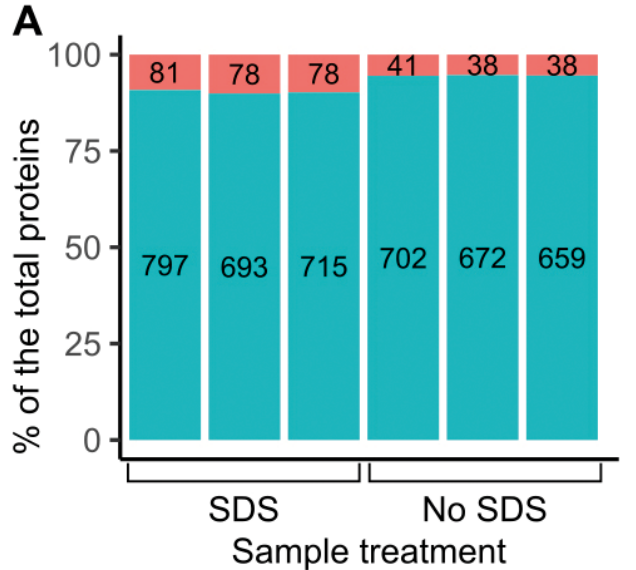

Transmembrane domain: $\begin{array}{ll}\text { Present } \\ \text { Absent }\end{array}$

B

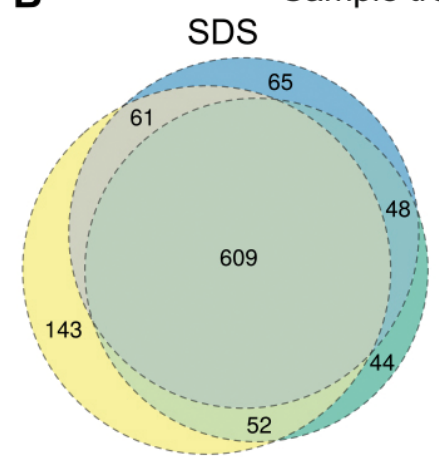

E PTHR11511 Larval storage protein/ phenoloxidase

PTHR11588 Tubulin-

PTHR22802 C-type lectin superfamily member -

PTHR11937 Actin-

ह PTHR11599 Proteasome subunit alpha/betaస్రాPTHR11461 Serine protease inhibitor, serpin(屯) PTHR19375 Heat shock protein 70kDaPTHR11353 Chaperonin PTHR24031 RNA helicasePTHR24260 Family not namedPTHR10288 KH domain containing RNA binding protein

PTHR11467 Histone $\mathrm{H} 1-$

PTHR11571 Glutathione S transferasePTHR23073 26S proteasome regulatory subunit

\section{All proteins:}

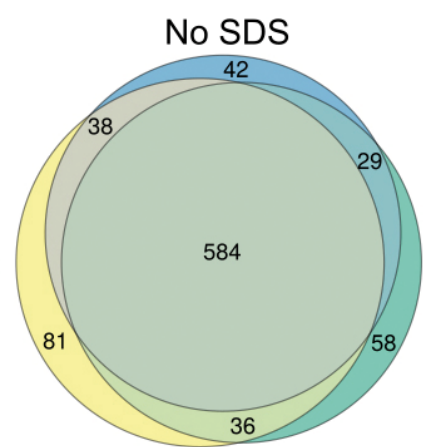

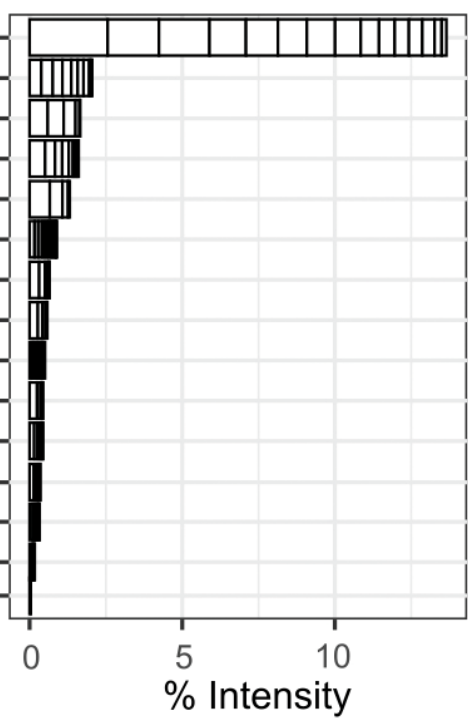

D Proteins found in all replicates:

Fig. 2. Protein diversity in hemocyte proteome of E. verrucosus. (A) Overall count of identified proteins in each of 6 replicates. Venn diagram presenting: the overlap between technical replicas of samples (B) with additional SDS and without SDS; the overlap of samples with SDS and without SDS to each other for (C) all detected proteins in general and (D) proteins found in all six replicates. All diagrams made with maintaining proportions while overlapping subset areas. (E) Major protein groups in the hemocyte proteome. Each rectangle corresponds to one predicted protein; the width of the rectangle is proportional to its intensity.

two more sequences belonged to the proteasome subunit family. Moreover, SDS-specific proteins contained one serine protease inhibitor, heat shock protein $70 \mathrm{kDa}$, RNA helicase, and glutathione S-transferase. In addition, seven sequences of the histone $\mathrm{H} 1$ family and three proteins of the $26 \mathrm{~S}$ protease regulatory subunit family were found. Overall, $19.7 \%$ of all SDS-specific proteins had a transmembrane domain in their sequences.

Second, we analyzed the diversity of protein families within the whole set of 1152 proteins. The larval storage protein / phenol oxidase family (PTHR11511) (about $13.6 \%$ of the total intensity of all replicates) was represented in the hemocyte proteome in the greatest amount. None of the protein sequences of this family that we discovered were SDS-specific and found in the sample with SDS only. Also, all these sequences lacked a transmembrane domain.

The third major group (1.7\% of the total intensity) comprised the proteins belonging to the C-type lectin superfamily (PTHR22802), which are probably involved in the molecular pattern recognition during immune response. In addition to lectins, we also found other pro- teins involved in the immune response, namely integrins, superoxide dismutase (SOD), scavenger receptors, and antimicrobial peptides.

In particular, we identified 17 proteins belonging to the PTHR22802 family and most of them contained C-type lectin-like domain (CTLD) and carbohydrate recognition domains (CRD) typical for lectins. In this family we found proteins similar to various lectins including galectin-4-like protein, galactose-specific lectin natectin-like and soluble scavenger receptor cysteinerich domain-containing protein SSC5D-like from amphipod Hyalella azteca, and partial mannose receptor from deep-sea shrimp Rimicaris exoculata (Table 1).

Many discovered proteins of the C-type lectin superfamily (PTHR22802) were found in both SDS and SDSfree samples, and only two sequences turned out to be SDS-specific. Despite the fact that C-type lectins belong to proteins with a transmembrane domain, none of them was found in all sequences of this family. A possible reason for the lack of the transmembrane domain is related to incomplete sequences (lack of $\mathrm{N}$ - or / and C-terminus). 
Table 1. Characteristic of some proteins found in E. verrucosus hemocyte proteome

\begin{tabular}{|c|c|c|c|c|c|c|c|}
\hline № & Protein ID & $\begin{array}{c}\text { Total } \\
\text { quantity, } \\
\text { ppm }\end{array}$ & Short NCBI annotation & Panther annotation & $\begin{array}{c}\text { SDS / } \\
\text { SDS-free }\end{array}$ & $\begin{array}{c}\mathrm{TM} \\
\text { domain }\end{array}$ & SP \\
\hline
\end{tabular}

Immune related

\begin{tabular}{|c|c|c|c|c|c|c|c|}
\hline 1 & $\begin{array}{l}\text { GHHK01014723.1|: } \\
\text { 331-801 }\end{array}$ & 5220.9 & - & $\begin{array}{l}\text { PTHR22802 C-type lectin } \\
\text { superfamily member }\end{array}$ & $3 / 3$ & - & + \\
\hline 2 & $\begin{array}{l}\text { GHHK01013999.1|: } \\
131-757\end{array}$ & 3874.0 & $\begin{array}{l}\text { soluble scavenger receptor } \\
\text { cysteine-rich domain-containing } \\
\text { protein SSC5D-like (Hyalella azteca) }\end{array}$ & $\begin{array}{l}\text { PTHR22802 C-type lectin } \\
\text { superfamily member }\end{array}$ & $3 / 3$ & - & + \\
\hline 3 & $\begin{array}{l}\text { GHHK01010725.1 |: } \\
2-352\end{array}$ & 4631.2 & $\begin{array}{l}\text { soluble scavenger receptor } \\
\text { cysteine-rich domain-containing } \\
\text { protein SSC5D-like }(H . \text { azteca) }\end{array}$ & - & $3 / 3$ & - & - \\
\hline 4 & $\begin{array}{l}\text { GHHK01013801.1|: } \\
\text { 59-421 }\end{array}$ & 137.2 & - & $\begin{array}{l}\text { PTHR22802 C-type lectin } \\
\text { superfamily member }\end{array}$ & $1 / 0$ & - & + \\
\hline 5 & $\begin{array}{l}\text { GHHK01007980.1|: } \\
182-973\end{array}$ & 138.4 & $\begin{array}{l}\text { galectin-4-like isoform X2 } \\
\text { (H. azteca) }\end{array}$ & PTHR1134 Galectin & $0 / 1$ & - & + \\
\hline 6 & GHHK01019889.1|:2-307 & 5948.9 & $\begin{array}{l}\text { galactose-specific lectin nattectin- } \\
\text { like }(H . \text { azteca) }\end{array}$ & $\begin{array}{l}\text { PTHR22802 C-type lectin } \\
\text { superfamily member }\end{array}$ & $3 / 3$ & - & - \\
\hline 7 & GHHK01029332.1|:1-306 & 9306.3 & $\begin{array}{l}\text { aggrecan core protein (Parambassis } \\
\text { ranga) }\end{array}$ & $\begin{array}{l}\text { PTHR22804 Aggrecan } \\
\text { / Versican proteoglycan }\end{array}$ & $3 / 3$ & - & - \\
\hline 8 & GHHK01027419.1|:3-476 & 1285.7 & $\begin{array}{l}\text { mannose receptor, partial } \\
\text { (Rimicaris exoculata) }\end{array}$ & $\begin{array}{l}\text { PTHR22802 C-type lectin } \\
\text { superfamily member }\end{array}$ & $3 / 3$ & - & - \\
\hline 9 & $\begin{array}{l}\text { GHHK01005065.1 |: } \\
1-1008\end{array}$ & 740.2 & $\begin{array}{l}\text { beta-1,3-glucan-binding protein- } \\
\text { like (H. azteca) }\end{array}$ & $\begin{array}{l}\text { PTHR10963 Glycosyl } \\
\text { hydrolase-related }\end{array}$ & $3 / 3$ & - & - \\
\hline 10 & $\begin{array}{l}\text { GHHK01013649.1|: } \\
81-2966\end{array}$ & 182.5 & $\begin{array}{l}\text { protein argonaute-2-like } \\
(H . \text { azteca) }\end{array}$ & $\begin{array}{l}\text { PTHR22891 Eukaryotic } \\
\text { translation initiation factor 2C }\end{array}$ & $2 / 3$ & - & + \\
\hline 11 & $\begin{array}{l}\text { GHHK01013084.1|: } \\
\text { 303-1385 }\end{array}$ & 88.6 & $\begin{array}{l}\text { RISC-loading complex subunit } \\
\text { tarbp2-like (H. azteca) }\end{array}$ & $\begin{array}{l}\text { PTHR10910 Eukaryote specific } \\
\text { dsRNA binding protein }\end{array}$ & $2 / 0$ & - & + \\
\hline 12 & $\begin{array}{l}\text { GHHK01001227.1|: } \\
125-1570\end{array}$ & 1402.8 & $\begin{array}{l}\text { DNA-binding protein } \\
43 \text { (Armadillidium nasatum) }\end{array}$ & - & $3 / 3$ & - & + \\
\hline 13 & $\begin{array}{l}\text { GHHK01013454.1|: } \\
\text { 32-1759 }\end{array}$ & 292.3 & $\begin{array}{l}\text { RNA-binding protein Nova-1 } \\
\text { (A. nasatum) }\end{array}$ & $\begin{array}{l}\text { PTHR10288 KH domain } \\
\text { containing RNA-binding } \\
\text { protein }\end{array}$ & $3 / 3$ & - & + \\
\hline 14 & $\begin{array}{l}\text { GHHK01012262.1|: } \\
\text { 159-4715 }\end{array}$ & 90357.4 & dual oxidase-like (H. azteca) & PTHR11972 NADPH oxidase & $1 / 0$ & - & + \\
\hline 15 & GHHK01017338.1|:2-469 & 1359.4 & lysozyme c-1-like (H. azteca) & PTHR11407 Lysozyme C & $2 / 3$ & - & - \\
\hline 16 & GHHK01015013.1|:1-621 & 22806.1 & ctenidin-1-like (H. azteca) & $\begin{array}{l}\text { PTHR19441 Whey acidic } \\
\text { protein WAP }\end{array}$ & $3 / 3$ & - & - \\
\hline 17 & GHHK01007931.1|:2-619 & 179.3 & $\begin{array}{l}\text { anti-lipopolysaccharide factor/ } \\
\text { Scygonadin (Trinorchestia } \\
\text { longiramus) }\end{array}$ & - & $3 / 0$ & - & - \\
\hline 18 & $\begin{array}{l}\text { GHHK01006680.1|: } \\
273-647\end{array}$ & 1447.8 & $\begin{array}{l}\text { anti-lipopolysaccharide factor/ } \\
\text { Scygonadin (T. longiramus) }\end{array}$ & - & $3 / 3$ & - & + \\
\hline 19 & $\begin{array}{l}\text { GHHK01004504.1|: } \\
610-4926\end{array}$ & 1857.6 & $\begin{array}{l}\text { alpha-2-macroglobulin-like isoform } \\
\text { X7 (H. azteca) }\end{array}$ & $\begin{array}{l}\text { PTHR11412 Macroglobulin } \\
\text { / complement }\end{array}$ & $3 / 3$ & - & + \\
\hline 20 & GHHK01018203.1|:3-533 & 893.8 & $\begin{array}{l}\text { alpha-2-macroglobulin-like isoform } \\
\text { X2 (H. azteca) }\end{array}$ & $\begin{array}{l}\text { PTHR11412 Macroglobulin } \\
\text { / complement }\end{array}$ & $0 / 3$ & - & - \\
\hline 21 & GHHK01016178.1|:1-447 & 6099.1 & $\begin{array}{l}\text { alpha-2-macroglobulin-like isoform } \\
\text { X9 (H. azteca) }\end{array}$ & $\begin{array}{l}\text { SF:PTHR11412 Macroglobulin } \\
\text { / complement }\end{array}$ & $3 / 3$ & - & - \\
\hline \multicolumn{8}{|c|}{ Housekeeping } \\
\hline 1 & $\begin{array}{l}\text { GHHK01030119.1 |: } \\
100-819\end{array}$ & 3829.2 & $\begin{array}{l}\text { alpha-tubulin, partial } \\
\text { (Macrobrachium nipponense) }\end{array}$ & PTHR11588 Tubulin & $3 / 3$ & - & + \\
\hline
\end{tabular}




\begin{tabular}{|c|c|c|c|c|c|c|c|}
\hline № & Protein ID & $\begin{array}{c}\text { Total } \\
\text { quantity, } \\
\text { ppm }\end{array}$ & Short NCBI annotation & Panther annotation & $\begin{array}{l}\text { SDS / } \\
\text { SDS-free }\end{array}$ & $\begin{array}{c}\mathrm{TM} \\
\text { domain }\end{array}$ & SP \\
\hline 2 & $\begin{array}{l}\text { GHHK01008410.1 |: } \\
\text { 2-805 }\end{array}$ & 3765.5 & $\begin{array}{l}\text { tubulin beta-1 chain-like } \\
(\text { H. azteca) }\end{array}$ & PTHR11588 Tubulin & $3 / 3$ & - & - \\
\hline 3 & $\begin{array}{l}\text { GHHK01029289.1 |: } \\
\text { 90-419 }\end{array}$ & 3157.3 & $\begin{array}{l}\text { tubulin alpha-1A chain-like } \\
\text { (Sipha flava) }\end{array}$ & PTHR11588 Tubulin & $3 / 3$ & - & + \\
\hline 4 & $\begin{array}{l}\text { GHHK01029314.1 |: } \\
60-1040\end{array}$ & 2149.2 & actin (Amphibalanus amphitrite) & PTHR11937 Actin & $2 / 3$ & - & + \\
\hline 5 & $\begin{array}{l}\text { GHHK01006379.1 |: } \\
166-1422\end{array}$ & 1344.5 & $\begin{array}{l}\text { actin-related protein 3-like } \\
\text { (H. azteca) }\end{array}$ & PTHR11937 Actin & $3 / 3$ & - & + \\
\hline 6 & $\begin{array}{l}\text { GHHK01009336.1 |: } \\
\text { 139-864 }\end{array}$ & 1612.8 & $\begin{array}{l}\text { proteasome subunit alpha } \\
\text { type-5-like (H. azteca) }\end{array}$ & $\begin{array}{l}\text { PTHR11599 Proteasome } \\
\text { subunit alpha / beta }\end{array}$ & $3 / 3$ & - & + \\
\hline 7 & $\begin{array}{l}\text { GHHK01004999.1 |: } \\
\text { 114-791 }\end{array}$ & 1210.2 & $\begin{array}{l}\text { proteasome subunit beta } \\
\text { type-6-like }(\text { H. azteca) }\end{array}$ & $\begin{array}{l}\text { PTHR11599 Proteasome } \\
\text { subunit alpha / beta }\end{array}$ & $3 / 3$ & - & + \\
\hline
\end{tabular}

TM - domain, transmembrane domain.

SP - signal peptide.

ppm - part per million.

The column "Short NCBI annotation" shows the description of proteins, which were the best match in the nr NCBI database for E. verrucosus hemocyte sequences. More detailed information about homolog ID and gene ontology from Panther database are provided in Table S1.

From the other immune molecules, we identified proteins similar to PRP beta-1,3-glucan-binding protein-like from H. azteca; proteins belonging to the RNA interference (RNAi)-based antiviral immune system, argonaute-2-like and RISC-loading complex subunit tarbp2-like from H.azteca, trans-activating response DNA-binding protein 43 and RNA-binding protein Nova- 1 from the woodlouse Armadillidium nasatum.

We also found proteins that demonstrate antimicrobial activity. Reactive oxygen species (ROS) are produced in hemocytes and play essential roles in crustacean antimicrobial immunity. In hemolymph, ROS are produced by dual oxidase (Yang et al., 2020), and we indeed found a protein similar to a dual oxidase-like from H.azteca in E. verrucosus hemocytes. Lysozyme is another enzyme involved in crustacean antimicrobial activity, which we identified in hemocyte proteome. Besides, we identified proteins for which the best match was ctenidin-1-like from $H$. azteca and anti-lipopolysaccharide factor/Scygonadin from Trinorchestia longiramus. In addition, three proteins we found were similar to the a2-macroglobulin glycoprotein from H.azteca and containing domains typical for this protein.

In addition to the immune-related proteins, we found a large number of protein products of housekeeping genes. Some of them are presented in Table 1. According to the PANTHER database, these proteins, which are present in the hemocyte proteome in the greatest amount, belong to various families such as PTHR11588 (tubulin), PTHR11937 (actin), PTHR11599 (proteasome subunit alpha / beta), etc. The cytoskeleton proteins tubulin and actin were second and fourth in number and accounted for $2.0 \%$ and $1.6 \%$ of the total intensity, respectively.

\section{Discussion}

Today, the study of the crustacean immune system is of great interest. Hemocytes, one of the main components of cellular immunity performing various functions during the immune response, are of particular interest. In this work, we present the first overview of an amphipod hemocyte proteome using the Baikal endemic species E. verrucosus as a model. We evaluated the proteome using a highly efficient LC-MS/MS system. Since we did not separate hemocytes according to their potential types, this work presents a general proteome of all functionally different types of hemocytes.

To date, no published studies analyzed hemocyte proteomes in amphipods. Nevertheless, there are several studies of hemocyte proteomes in other crustaceans (Meng et al., 2014; Hou et al., 2016; Sun et al., 2017; Xu et al., 2018; Hernández-Pérez et al., 2019; Söderhäll and Junkunlo, 2019). Unfortunately, the comparison of the proteome obtained in this work with the proteomes of other crustaceans directly, i.e., at the level of amino acid sequences, is difficult or impossible, because these articles do not contain references to protein lists with human-readable annotation or sequences required to generate annotations compatible with our data. As the main hemocyte function is the immune response, we focus on the immune components and the most abundant proteins of hemocytes, comparing it with the available information about hemocyte proteomes of other invertebrates.

One of the proteins that are found in large quantities in the humoral fraction of hemolymph is hemocyanin, which is usually involved in oxygen transfer. Despite 
the fact that hemocyanin circulates in the hemolymph plasma, we found a number of its isoforms in the hemocytes of E. verrucosus. We cannot rule out the possibility that it is due to insufficient washing of hemocytes from the humoral fraction. However, Chongsatja et al. (2007) and Hou et al. (2016) also found hemocyanin in the hemocyte proteomes of such crustaceans as the white shrimp Litopenaeus (Penaeus) vannamei and freshwater prawn Macrobrachium (Chongsatja et al., 2007; Hou et al., 2016). Hemocyanins belong to the PTHR11511 (larval storage protein/ phenoloxidase) family according to the Panther database, which is the most diverse group of identified proteins in E. verrucosus hemocytes (Fig. 2B). These proteins are not only involved in oxygen transfer, but may also perform immune functions. Since hemocyanins are phylogenetically closely related to phenol oxidases, these hemocyanins may act as phenol oxidases and participate in the melanization process (Terwilliger, 2015; Coates and Costa-Paiva, 2020). The works of Adachi et al. $(2001,2003)$ also demonstrated the phenoloxidase function of hemocyanin in vitro under certain conditions (Adachi, Hirata, Nagai and Sakaguchi, 2001; Adachi, Hirata, Nishioka and Sakaguchi, 2003).

Also, some of the biggest protein families in the hemocyte proteome of E.verrucosus according to the Panther classification was the C-type lectin superfamily (PTHR22802). C-type lectins belong to PRPs, which are involved in the recognition of foreign particles and activate signaling cascades (Mydlarz, Jones and Harvell, 2006). Recognition occurs due to binding to the membrane surface of microorganisms through the carbohydrate-recognition domain (CRD-domain), which is responsible for binding to saccharides (Zelensky and Gready, 2005). These proteins were found in the studies by Xu et al. (2018) and Hernández-Pérez et al. (2019) devoted to the hemocyte proteomes of other crustaceans. The proteins we found were similar to various lectins. Three sequences were similar to lectins with signal peptides, which are involved in the recognition of PAMP and may activate the immune response of hemocytes. Another sequence without a signal peptide was similar to galectin, which can circulate in hemolymph plasma and in the intracellular space (Hou et al., 2015).

We also found the mannose receptor, which is among the best-characterized C-type lectins. It binds mannosyl or glycoconjugate ligands on many bacteria, fungi, and protozoan parasites to mediate subsequent responses (Rich et al., 2008). Granular hemocytes of the crayfish Pacifastacus leniusculus were released from the vesicles with a mannose receptor under treatment of $\mathrm{Ca}^{2+}$ ionophore (Sricharoen, Kim, Tunkijjanukij and Söderhäll, 2005).

Other PRPs have also been found in the proteome of E. verrucosus hemocytes. These are $\beta$-1,3-glucan binding protein (BGBP), and leucine-rich repeat (LRR) pro- teins. BGBP specifically binds to such components of the fungi cell walls as $\beta$-1,3-glucan in the shrimp Penaeus semisulcatus (Du, Zhao and Wang, 2007; Lai et al., 2011; Sivakamavalli and Vaseeharan, 2013). Studies in two Brazilian shrimp species (Farfantepenaeus paulensis and Litopenaeus schmitti) showed that their BGBPs induce the agglutination reaction with yeasts (Goncalves et al., 2012). The presence of this protein in the hemocytes of E. verrucosus may explain the response of hemocytes to yeast cells shown earlier (Shchapova et al., 2019).

A2-macroglobulin ( $\alpha 2-M)$ is an important innate immunity-related protein found in the hemolymph plasma of all major metazoan taxa. It binds to secreted proteases of invading pathogens to deactivate them (Armstrong, 2010). At least one of the three $\alpha 2-\mathrm{M}$ proteins we discovered clearly lacks a signal peptide (the other two sequences are incomplete), which indicates that it is not synthesized outward on its own and may enter the hemolymph plasma during hemocyte degranulation. $\alpha 2-\mathrm{M}$ was found in the proteome of not only various crustaceans (Meng et al., 2014; Hou et al., 2016; Xu et al., 2018; Zhu et al., 2018) but also mollusks. For example, in the works published by Collins et al. (2012) and Leprêtre et al. (2019), a2-M was identified in the hemocyte proteome of the Hawaiian bobtail squid Euprymna scolopes and zebra mussel Dreissena polymorpha, respectively (Collins, Schleicher, Rader and Nyholm, 2012; Leprêtre et al., 2019).

The superoxide dismutase (SOD) we discovered, belonging to the group of antioxidant enzymes, neutralizes the superoxide anion, which is formed during the immune response (Holmblad and Söderhäll, 1999). This protein is present in the hemocytes of Chinese shrimp Fenneropenaeus chinensis (Li et al., 2014) and snail Biomphalaria glabrata (Dinguirard et al., 2018). This protein was also found in crayfish Pacifastacus leniusculus granulocytes as a useful biomarker for this cell (Söderhäll and Junkunlo, 2019).

A serine protease inhibitor protein, serpin, which controls protease inhibition during the immune response, was also identified (Gatto et al., 2013). Many serine protease inhibitors were found in the proteomes of hemocytes Chinese mitten crab Eriocheir sinensis, red swamp crawfish Procambarus clarkii, and white shrimp L. vannamei (Meng et al., 2014; Xu et al., 2018; Hernández-Pérez et al., 2019).

We also found a protein for which the antimicrobial peptide ctenidin-1-like was the best match in the $\mathrm{nr}$ NCBI database. Ctenidin shows antimicrobial properties against gram-negative bacteria and was found in the spider Cupiennius salei (Baumann et al., 2010). It should be noted that this antimicrobial peptide was not found in other studies of crustacean hemocyte proteomes. In addition to ctenidin, we found other sequences for which the best match were proteins with antibiotic activity (anti-lipopolysaccharide factor / Scygonadin and 
scavenger receptor cysteine-rich domain-containing protein SSC5D-like). We found a number of unknown proteins that were unidentified in the databases and seem to be specific for amphipods only, and therefore may be promising for further study of immune defense.

Finally, we compared the hemocyte proteome of E.verrucosus with the whole organism proteome of a closely related species, Eulimnogammarus cyaneus (Bedulina et al., 2020). At the level of the whole organism, enzymes of energetic metabolism dominate in the proteome, while this is unobserved in the hemocyte proteome.

It was shown that malacostracans, including amphipods, isopods and decapods, have an RNAi-based antiviral immune system. The RNA-induced silencing complex (RISC) is the component of RNAi that includes argonaute- 2 protein and trans-activating response RNAbinding protein (Lai and Aboobaker, 2017). We found Argonaute-2-like, RISC-loading complex, RNA-binding protein Nova-1, and TAR DNA-binding protein. It was shown that the RNA-binding protein Nova-1 may function in regulating viral RNA transcription (Buckanovich and Darnell, 1997). TAR DNA-binding protein of Armadillidium vulgare functions as a DNA and RNA binding protein, which may also indicate its function in antiviral defense (UniProtKB - A0A444SUA2 (A0A444SUA2 ARMVU)).

In the proteome of E. verrucosus hemocytes, a dual oxidase-like protein was found. This protein is a component producing ROS in response to microbial or parasite invasions. Dinguirard et al. (2018) showed the presence of dual oxidase-like was shown in the proteome of the hemocytes of B. glabrata strains resistant to the sporocysts of Schistosoma mansoni; however, sensitive strains of hemocytes did not possess this protein. This protein was found in the proteome of E. verrucosus hemocytes without treatment with any pathogens, thus it can be assumed that E. verrucosus amphipods have active immune protection based on producing ROS. The authors of the article (Söderhäll and Junkunlo, 2019) argue that dual oxidase may be one of the markers of populations and subpopulations of semigranulocytes. Also, in the population of crayfish P. leniusculus semigranulocytes, lysozyme was observed. In proteome semigranulocytes (hyalinocytes) of the Chinese shrimp F. chinensis lysozyme was also found (Zhu et al., 2018). However, in our work, we did not separate the population from different types of hemocytes, but based on the presence of the dual oxidase-like protein we can discuss the presence of semigranulocytes of E. verrucosus hemocytes besides obvious granulocytes and plasmocytes.

Besides proteins related to the immune function of hemocytes, we have found some of the most abundant proteins that perform various cell functions. We have demonstrated the presence of tubulin and actin proteins associated with the structure of the cytoskeleton. These proteins occupy positions 2 and 4 in the graph of protein abundance in the proteome (Fig. 2E). Cytoskeletal proteins are an essential part of cells and were found in the hemocyte proteome of various crustaceans. Both of these proteins are found in hemocytes of the mud crab Scylla paramamosain (Sun et al., 2017) and the Chinese shrimp F. chinensis (Li et al., 2014; Zhu et al., 2018). The microfilament-forming actin we identified was also found in the hemocyte proteomes of the Chinese mitten crab E. sinensis (Meng et al., 2014).

The sixth most abundant protein family in the hemocyte proteome was PTHR11599 (proteasome subunit alpha/beta family), according to the Panther database. Proteasomes are involved in the degradation of proteins and are found in cells of both eukaryotes and prokaryotes (Fort, Kajava, Delsuc and Coux, 2015). The presence of proteasome proteins was shown in the proteome of hemocytes of such crustaceans as the Chinese shrimp F. chinensis (Zhu et al., 2018) and the whiteleg shrimp L. vannamei (Chongsatja et al., 2007).

We found proteins belonging to the PTHR19375 (heat shock protein $70 \mathrm{kDa}$ ) family, which also are the most represented proteins in the proteome of E. verrucosus hemocytes and occupy the eighth place in the list of the most represented families (Fig. 2E). Heat shock proteins (HSPs) ensure proper folding and degradation of proteins, are activated under stress effects, and are present in both prokaryotic and eukaryotic cells (Hartl and Hayer-Hartl, 2002; Robert, 2003). It was also shown that members of HSPs and HSP70, in particular, are involved in the activation of several immune pathways in crustaceans (Junprung, Supungul and Tassanakajon, 2020).

The presence of these physiologic proteins has been shown in the red swamp crawfish Procambarus clarkii (Xu et al., 2018) and the Chinese shrimp F. chinensis (Li et al., 2014; Zhu et al., 2018). Other proteins of this class, such as HSP60, are found in hemocytes of the Chinese mitten crab E. sinensis (Meng et al., 2014) and the freshwater prawn Macrobrachium rosenbergii (Hou et al., 2016); HSP90 is found in hemocytes of the mud crab S. paramamosain (Sun et al., 2017) and the Chinese shrimp F. chinensis (Zhu et al., 2018).

Among proteins performing physiological functions in the proteome of E. verrucosus hemocytes, we also found proteins that belong to the families PTHR24031 (RNA helicase) and PTHR11467 (histone $\mathrm{H1}$ ), which are ranked 10 and 13 in the list of the most represented proteins. According to the literature, the RNA helicases enzymes involved in breaking the hydrogen bonds of RNA chains are present in the proteome of the Chinese shrimp F. chinensis hemocytes ( $\mathrm{Li}$ et al., 2014). Histones of various types, both linker and core, were shown in hemocyte proteome of such crustaceans as white shrimp L. vannamei (Hernández-Pérez et al., 
2019), Chinese shrimp F. chinensis (Li et al., 2014; Zhu et al., 2018), and in snail B. glabrata hemocytes (Dinguirard et al., 2018).

\section{Conclusion}

Thus, in this work, for the first time for amphipods in general, we analyzed the hemocyte proteome of the Baikal endemic E. verrucosus. Thereby, we found proteins that are directly or indirectly involved in the immune response and protein products of housekeeping genes. In particular, we found several types of PRPs including lectins and scavenger receptors, antimicrobial peptides, inhibitor proteins like A2-M and serpin and antioxidant enzyme SOD. We have also found proteins with unknown functions that may be characteristic of this crustacean species and are promising for further study. The presented results can be used for better understanding the immune processes in the organism of Baikal amphipods.

\section{Acknowledgments}

The authors would like to acknowledge Dr. Anton Gurkov for his valuable advice and recommendations and Polina Lipaeva for her advice on data analysis. We would like to acknowledge Dr. Kseniya Vereshchagina for the photo of E. verrucosus. We also wish to thank the Advanced Mass Spectrometry Core Facility (Skoltech, Moscow) for their assistance with LC-MS/MS analysis.

\section{References}

Adachi, K., Hirata, T., Nagai, K., and Sakaguchi, M. 2001. Hemocyanin a most likely inducer of black spots in kuruma prawn Penaeus japonicus during storage. Journal of Food Science 66(8):1130-1136. https://doi. org/10.1111/j.1365-2621.2001.tb16093.x

Adachi, K., Hirata, T., Nishioka, T., and Sakaguchi, M. 2003. Hemocyte components in crustaceans convert hemocyanin into a phenoloxidase-like enzyme. Comparative Biochemistry and Physiology Part B: Biochemistry and Molecular Biology 134(1):135-141. https://doi.org/10.1016/ S1096-4959(02)00220-8

Amin, O. M., Heckmann, R. A., and Baldanova, D. R. 2015. Revisiting Echinorhynchid acanthocephalans in Lake Baikal with the use of scanning electron microscopy, with some taxonomic reconsiderations. Comparative Parasitology 82(1):29-39. https://doi.org/10.1654/4750.1

Armenteros, J.J.A., Tsirigos, K.D., Sønderby, C. K., Petersen, T. N., Winther, O., Brunak, S., Von Heijne G., and Nielsen, H. 2019. SignalP 5.0 improves signal peptide predictions using deep neural networks. Nature Biotechnology 37(4):420-423. https://doi.org/10.1038/s41587019-0036-z

Armstrong, P. B. 2010. Role of a2-macroglobulin in the immune responses of invertebrates. Invertebrate Survival Journal 7(2):165-180.

Axenov-Gribanov, D., Bedulina, D., Shatilina, Z., Jakob, L., Vereshchagina, K., Lubyaga, Y., Gurkov, A., Shchapova, E., Luckenbach, T., Lucassen, M., Sartoris, F. J., Pörtner, H.O., and Timofeyev, M. 2016. Thermal preference ranges correlate with stable signals of universal stress markers in Lake Baikal endemic and Holarctic amphipods. PloS One 11(10):e0164226. https://doi. org/10.1371/journal.pone.0164226

Baumann, T., Kämpfer, U., Schürch, S., Schaller, J., Largiader, C., Nentwig, W., and Kuhn-Nentwig, L. 2010. Ctenidins: antimicrobial glycine-rich peptides from the hemocytes of the spider Cupiennius salei. Cellular and Molecular Life Sciences 67(16):2787-2798. https://doi.org/10.1007/ s00018-010-0364-0

Bazikalova, A. Y. 1945. Amphipods of Lake Baikal. Proceedings of Baikal Limnological Station 11:1-440.

Bedulina, D. S., Gurkov, A. N., Baduev, B. K., Borvinskaya, E. V., Dimova, M. D., and Timofeyev, M. A. 2016. Preliminary analysis of hemocyanins in hemolymph plasma of Baikal endemic amphipods. Journal of Stress Physiology \& Biochemistry 12(1):74-86.

Bedulina, D., Drozdova, P., Gurkov, A., Von Bergen, M., Stadler, P. F., Luckenbach, T., Timofeyev M., and Kalkhof, S. 2020. Proteomics reveals sex-specific heat shock response of Baikal amphipod Eulimnogammarus cyaneus. Science of the Total Environment 763:143008. https:// doi.org/10.1016/j.scitotenv.2020.143008

Bondad-Reantaso, M. G., Subasinghe, R. P., Josupeit, H., Cai, J., and Zhou, X. 2012. The role of crustacean fisheries and aquaculture in global food security: past, present and future. Journal of Invertebrate Pathology 110(2):158-165. https://doi.org/10.1016/j.jip.2012.03.010

Bradford, M. M. 1976. A rapid and sensitive method for the quantitation of microgram quantities of protein utilizing the principle of protein-dye binding. Analytical Biochemistry 72(1-2):248-254. https://doi.org/10.1016/00032697(76)90527-3

Buchfink, B., Xie, C., and Huson, D. H. 2015. Fast and sensitive protein alignment using DIAMOND. Nature Methods 12(1):59-60. https://doi.org/10.1038/nmeth.3176

Buckanovich, R.J. and Darnell, R.B. 1997. The neuronal RNA binding protein Nova-1 recognizes specific RNA targets in vitro and in vivo. Molecular and Cellular Biology 17(6):3194-3201. https://doi.org/10.1128/ mcb.17.6.3194

Cerenius, L., Jiravanichpaisal, P., Liu, H. P., and Soderhall, I. 2010. Crustacean immunity. Invertebrate Immunity 708:239-259. https://doi.org/10.1007/978-1-4419-80595_13

Chang, E. S. and Thiel, M. V. 2015. Physiological Regulation. The natural history of the Crustacea. 512 pp. Oxford University Press, Oxford; New York.

Charif, D. and Lobry, J. R. 2007. SeqinR 1.0-2: a contributed package to the $\mathrm{R}$ project for statistical computing devoted to biological sequences retrieval and analysis; pp. 207-232 in Bastolla, U., Porto, M., Roman, H. E., and Vendruscolo, M. (eds), Structural approaches to sequence evolution. Biological and medical physics, biomedical engineering. Springer, Berlin, Heidelberg. https://doi. org/10.1007/978-3-540-35306-5_10

Chongsatja, P. O., Bourchookarn, A., Lo, C. F., Thongboonkerd, V., and Krittanai, C. 2007. Proteomic analysis of differentially expressed proteins in Penaeus vannamei hemocytes upon Taura syndrome virus infection. Proteomics 7(19):3592-3601. https://doi.org/10.1002/ pmic. 200700281

Coates, C. J. and Costa-Paiva, E. M. 2020. Multifunctional roles of hemocyanins. Vertebrate and Invertebrate Respiratory Proteins, Lipoproteins and other Body Fluid Proteins 94:233-250. https://doi.org/10.1007/978-3-030-4176979

Collins, A. J., Schleicher, T. R., Rader, B. A., and Nyholm, S. V. 2012. Understanding the role of host hemocytes in 
a squid/vibrio symbiosis using transcriptomics and proteomics. Frontiers in Immunology 3:91. https://doi. org/10.3389/fimmu.2012.00091

Dimova, M., Madyarova, E., Gurkov, A., Drozdova, P., Lubyaga, Y., Kondrateva, E., Adelshin, R., and Timofeyev, M. 2018. Genetic diversity of Microsporidia in the circulatory system of endemic amphipods from different locations and depths of ancient Lake Baikal. PeerJ 6:e5329. https://doi.org/10.7717/peerj.5329

Dinguirard, N., Cavalcanti, M. G., Wu, X. J., Bickham-Wright, U., Sabat, G., and Yoshino, T.P. 2018. Proteomic analysis of Biomphalaria glabrata hemocytes during in vitro encapsulation of Schistosoma mansoni sporocysts. Frontiers in Immunology 9:2773. https://doi.org/10.3389/ fimmu.2018.02773

Drozdova, P., Rivarola-Duarte, L., Bedulina, D., Axenov-Gribanov, D., Schreiber, S., Gurkov, A., Shatilina, Z., Vereshchagina, K., Lubyaga, Y., Madyarova, E., Otto, C., Jühling, F., Busch, W., Jakob, L., Lucassen, M., Sartoris, F. J., Hackermüller, J., Hoffmann, S., Pörtner, H. O., Luckenbach, T., Timofeyev, M., and Stadler, P. F. 2019. Comparison between transcriptomic responses to short-term stress exposures of a common Holarctic and endemic Lake Baikal amphipods. BMC Genomics 20(1):1-14. https://doi.org/10.1186/s12864-019-6024-3

Du, X. J., Zhao, X. F., and Wang, J.X. 2007. Molecular cloning and characterization of a lipopolysaccharide and $\beta-1$, 3-glucan binding protein from fleshy prawn (Fenneropenaeus chinensis). Molecular Immunology 44(6):10851094. https://doi.org/10.1016/j.molimm.2006.07.288

Fort, P., Kajava, A. V., Delsuc, F., and Coux, O. 2015. Evolution of proteasome regulators in eukaryotes. Genome Biology and Evolution 7(5):1363-1379. https://doi.org/10.1093/ gbe/evv068

Gatto, M., laccarino, L., Ghirardello, A., Bassi, N., Pontisso, P., Punzi, L., Shoenfeld, Y., and Doria, A. 2013. Serpins, immunity and autoimmunity: old molecules, new functions. Clinical Reviews in Allergy \& Immunology 45(2):267280. https://doi.org/10.1007/s12016-013-8353-3

George, S. K. and Dhar, A. K. 2010. An improved method of cell culture system from eye stalk, hepatopancreas, muscle, ovary, and hemocytes of Penaeus vannamei. In Vitro Cellular \& Developmental Biology-Animal 46(9):801810. https://doi.org/10.1007/s11626-010-9343-x

Goncalves, P., Vernal, J., Rosa, R. D., Yepiz-Plascencia, G., de Souza, C. R. B., Barracco, M. A., and Perazzolo, L. M. 2012. Evidence for a novel biological role for the multifunctional $\beta$-1, 3-glucan binding protein in shrimp. Molecular Immunology 51(3-4):363-367. https://doi.org/10.1016/j. molimm.2012.03.032

Haas, B.J., Papanicolaou, A., Yassour, M., Grabherr, M., Blood, P. D., Bowden, J., Couger, M. B., Eccles, D., Li, B., Lieber, M., and MacManes, M. D. 2013. De novo transcript sequence reconstruction from RNA-seq using the Trinity platform for reference generation and analysis. $\mathrm{Na}$ ture Protocols 8(8):1494-1512. https://doi.org/10.1038/ nprot.2013.084

Hartl, F. U. and Hayer-Hartl, M. 2002. Molecular chaperones in the cytosol: from nascent chain to folded protein. Science 295(5561):1852-1858. https://doi.org/10.1126/science. 1068408

Hernández-Pérez, A., Zamora-Briseño, J.A., Ruiz-May, E., Pereira-Santana, A., Elizalde-Contreras, J.M., PozosGonzález, S., Torres-Irineoe, E., Hernández-López, J., Gaxiola-Cortés, M. G., and Rodríguez-Canul, R. 2019. Proteomic profiling of the white shrimp Litopenaeus vannamei (Boone, 1931) hemocytes infected with white spot syndrome virus reveals the induction of allergy-related proteins. Developmental \& Comparative Immunology 91:37-49. https://doi.org/10.1016/j.dci.2018.10.002

Holmblad, T. and Söderhäll, K. 1999. Cell adhesion molecules and antioxidative enzymes in a crustacean, possible role in immunity. Aquaculture 172(1-2):111-123. https://doi. org/10.1016/S0044-8486(98)00446-3

Hou, F., Liu, Y., He, S., Wang, X., Mao, A., Liu, Z., Sun, C., and Liu, X. 2015. A galectin from shrimp Litopenaeus vannamei is involved in immune recognition and bacteria phagocytosis. Fish \& Shellfish Immunology 44(2):584-591. https://doi.org/10.1016/j.fsi.2015.03.017

Hou, L., Xiu, Y., Wang, J., Liu, X., Liu, Y., Gu, W., Wang, W., and Meng, Q. 2016. iTRAQ-based quantitative proteomic analysis of Macrobrachium rosenbergii hemocytes during Spiroplasma eriocheiris infection. Journal of Proteomics 136:112-122. https://doi.org/10.1016/j. jprot.2015.12.026

Huerta-Cepas, J., Forslund, K., Coelho, L. P., Szklarczyk, D., Jensen, L.J., Von Mering, C., and Bork, P. 2017. Fast genome-wide functional annotation through orthology assignment by eggNOG-mapper. Molecular Biology and Evolution 34(8):2115-2122. https://doi.org/10.1093/molbev/msx148

Huerta-Cepas, J., Szklarczyk, D., Heller, D., Hernández-Plaza, A., Forslund, S. K., Cook, H., Mende, D. R., Letunic, I., Rattei, T., Jensen, L. J., and von Mering, C. 2019. eggNOG 5.0: a hierarchical, functionally and phylogenetically annotated orthology resource based on 5090 organisms and 2502 viruses. Nucleic Acids Research 47(D1):D309D314. https://doi.org/10.1093/nar/gky1085

Ironside, J. E. and Wilkinson, T.J. 2018. Accumulation and exchange of parasites during adaptive radiation in an ancient lake. International Journal for Parasitology 48(34):297-307. https://doi.org/10.1016/j.ijpara.2017.10.003

Junprung, W., Supungul, P., and Tassanakajon, A. 2021. Structure, gene expression, and putative functions of crustacean heat shock proteins in innate immunity. Developmental \& Comparative Immunology 103875. https://doi. org/10.1016/j.dci.2020.103875

Kamaltynov, R. M. 1999. On the evolution of Lake Baikal amphipods. Crustaceana 72(8):921-931. https://doi. org/10.1163/156854099503825

Kaygorodova, I. A. and Natyaganova, A. V. 2012. The first cytogenetic report of the endemic fish leech Baicalobdella torquata (Hirudinida, Piscicolidae) from Lake Baikal. Lauterbornia 75:63-70.

Kravtsova, L. S., Kamaltynov, R. M., Karabanov, E. B., Mekhanikova, I. V., Sitnikova, T. Y., Rozhkova, N. A., Slugina, Z. V., Izhboldina, L. A., Weinberg, I. V., Akinshina, T. V., and Sherbakov, D.Y. 2004. Macrozoobenthic communities of underwater landscapes in the shallow-water zone of southern Lake Baikal. Hydrobiologia 522(1):193-205. https://doi.org/10.1023/B:HYDR.0000029979.68265.3e

Krogh, A., Larsson, B., Von Heijne, G., and Sonnhammer, E. L. 2001. Predicting transmembrane protein topology with a hidden Markov model: application to complete genomes. Journal of Molecular Biology 305(3):567-580. https://doi.org/10.1006/jmbi.2000.4315

Lai, A. G. and Aboobaker, A. A. 2017. Comparative genomic analysis of innate immunity reveals novel and conserved components in crustacean food crop species. BMC Genomics 18(1):1-26. https://doi.org/10.1186/s12864-0173769-4

Lai, X., Kong, J., Wang, Q., Wang, W., and Meng, X. 2011. Cloning and characterization of a $\beta$-1, 3-glucan-binding protein from shrimp Fenneropenaeus chinensis. Molecular Biology Reports 38(7):4527-4535. https://doi.org/10.1007/ s11033-010-0583-3 
Leprêtre, M., Almunia, C., Armengaud, J., Salvador, A., Geffard, A., and Palos-Ladeiro, M. 2019. The immune system of the freshwater zebra mussel, Dreissena polymorpha, decrypted by proteogenomics of hemocytes and plasma compartments. Journal of Proteomics 202:103366. https://doi.org/10.1016/j.jprot.2019.04.016

Li, W., Tang, X., Xing, J., Sheng, X., and Zhan, W. 2014. Proteomic analysis of differentially expressed proteins in Fenneropenaeus chinensis hemocytes upon white spot syndrome virus infection. PloS One 9(2):e89962. https:// doi.org/10.1371/journal.pone.0089962

Madyarova, E. V., Adelshin, R. V., Dimova, M. D., Axenov-Gribanov, D. V., Lubyaga, Y. A., and Timofeyev, M. A. 2015. Microsporidian parasites found in the hemolymph of four baikalian endemic amphipods. PloS One 10(6):e0130311. https://doi.org/10.1371/journal.pone.0130311

Meng, Q., Hou, L., Zhao, Y., Huang, X., Huang, Y., Xia, S., Gu, W., and Wang, W. 2014. iTRAQ-based proteomic study of the effects of Spiroplasma eriocheiris on Chinese mitten crab Eriocheir sinensis hemocytes. Fish \& Shellfish Immunology 40(1):182-189. https://doi.org/10.1016/j.fsi.2014.06.029

Mi, H., Muruganujan, A., Huang, X., Ebert, D., Mills, C., Guo, X., and Thomas, P. D. 2019. Protocol update for large-scale genome and gene function analysis with the PANTHER classification system (v. 14.0). Nature Protocols 14(3):703721. https://doi.org/10.1038/s41596-019-0128-8

Mydlarz, L. D., Jones, L. E., and Harvell, C. D. 2006. Innate immunity, environmental drivers, and disease ecology of marine and freshwater invertebrates. Annual Review of Ecology, Evolution, and Systematics 37:251-288. https:// doi.org/10.1146/annurev.ecolsys.37.091305.110103

Perez-Riverol, Y., Csordas, A., Bai, J., Bernal-Llinares, M., Hewapathirana, S., Kundu, D. J., Inuganti, A., Griss, J., Mayer, G., Eisenacher, M., Pérez, E., Uszkoreit, J., Pfeuffer, J., Sachsenberg, T., Yılmaz, S.., Tiwary, S., Cox, J., Audain, E., Walzer, M., Jarnuczak, A. F., Ternent, T., Brazma, A., and Vizcaíno, J.A. 2019. The PRIDE database and related tools and resources in 2019: improving support for quantification data. Nucleic Acids Research 47(D1):D442D450. https://doi.org/10.1093/nar/gky1106

Protasov, E.S., Axenov-Gribanov, D. V., Rebets, Y. V., Voytsekhovskaya, I. V., Tokovenko, B. T., Shatilina, Z. M., Luzhetskyy, A. N., and Timofeyev, M. A. 2017. The diversity and antibiotic properties of actinobacteria associated with endemic deepwater amphipods of Lake Baikal. Antonie Van Leeuwenhoek 110(12):1593-1611. https:// doi.org/10.1007/s10482-017-0910-y

Rich, R., Fleisher, T., Shearer, W., Schroeder, H., Frew, A., and Weyand, C. 2008. Clinical immunology: Principles and practice, $3^{\text {rd }}$ ed., Mosby, 1616 pp. https://doi. org/10.1016/B978-0-323-04404-2.X0110-8

Robert, J. 2003. Evolution of heat shock protein and immunity. Developmental \& Comparative Immunology 27(6-7):449464. https://doi.org/10.1016/S0145-305X(02)00160-X

Rowley, A. F. 2016. The immune system of Crustaceans. Encyclopedia of immunobiology. Academic Press, Elsevier 1:437-453. https://doi.org/10.1016/B978-0-12-3742797.12005-3

Shchapova, E., Nazarova, A., Gurkov, A., Borvinskaya, E., Rzhechitskiy, Y., Dmitriev, I., Meglinski I., and Timofeyev, M. 2019. Application of PEG-Covered nonbiodegradable polyelectrolyte microcapsules in the crustacean circulatory system on the example of the amphipod Eulimnogammarus verrucosus. Polymers 11(8):1246. https://doi.org/10.3390/polym11081246
Sivakamavalli, J. and Vaseeharan, B. 2013. Purification, characterization and functional analysis of a novel $\beta-1$, 3-glucan binding protein from green tiger shrimp Penaeus semisulcatus. Fish \& Shellfish Immunology 35(3):689696. https://doi.org/10.1016/j.fsi.2013.05.017

Sket, B., Morino, H., Takhteev, V., and Rogers, D. C. 2019. Phylum Arthropoda: Malacostraca: Amphipoda. Thorp and Covich's Freshwater Invertebrates 4:808-836.

Söderhäll, I. and Junkunlo, K. 2019. A comparative global proteomic analysis of the hematopoietic lineages in the crustacean Pacifastacus leniusculus. Developmental \& Comparative Immunology 92:170-178. https://doi. org/10.1016/j.dci.2018.11.016

Sricharoen, S., Kim, J.J., Tunkijjanukij, S., and Söderhäll, I. 2005. Exocytosis and proteomic analysis of the vesicle content of granular hemocytes from a crayfish. Developmental \& Comparative Immunology 29(12):1017-1031. https://doi.org/10.1016/j.dci.2005.03.010

Sun, B., Wang, Z., Wang, Z., Ma, X., and Zhu, F. 2017. A proteomic study of hemocyte proteins from mud crab (Scylla paramamosain) infected with white spot syndrome virus or Vibrio alginolyticus. Frontiers in Immunology 8:468. https://doi.org/10.3389/fimmu.2017.00468

Sun, D., Wang, N., and Li, L. 2012. Integrated SDS removal and peptide separation by strong-cation exchange liquid chromatography for SDS-assisted shotgun proteome analysis. Journal of Proteome Research 11(2):818-828. https://doi.org/10.1021/pr200676v

Tang, H., Finn, R. D., and Thomas, P. D. 2019. TreeGrafter: phylogenetic tree-based annotation of proteins with Gene Ontology terms and other annotations. Bioinformatics 35(3):518520. https://doi.org/10.1093/bioinformatics/bty625

Team, R. C. 2019. R: A Language and Environment for Statistical Computing.

Terwilliger, N. B. 2015. Oxygen transport proteins in Crustacea: hemocyanin and hemoglobin. Physiology (4):359-390.

Vaudel, M., Burkhart, J. M., Zahedi, R.P., Oveland, E., Berven, F. S., Sickmann, A., Martens, L., and Barsnes, H. 2015. PeptideShaker enables reanalysis of MS-derived proteomics data sets. Nature Biotechnology 33(1):22-24. https://doi.org/10.1038/nbt.3109

Watling, L. and Thiel, M. 2013. Functional Morphology and Diversity. The natural history of the Crustacea. 516 pp. Oxford University Press, Oxford; New York.

Wickham, H. 2016. ggplot2-Elegant graphics for data analysis. Springer International Publishing. Cham, Switzerland.

Xu, Y., Shi, J., Hao, W., Xiang, T., Zhou, H., Wang, W., Meng, Q., and Ding, Z. 2018. iTRAQ-based quantitative proteomic analysis of Procambarus clakii hemocytes during Spiroplasma eriocheiris infection. Fish \& Shellfish Immunology 77:438-444. https://doi.org/10.1016/j.fsi.2018.04.005

Yang, Q., Sun, Z., Zhou, Y., Tran, N. T., Zhang, X., Lin, Q., Zhou, C., Zhang, Y., and Li, S. 2020. SpATF2 participates in maintaining the homeostasis of hemolymph microbiota by regulating dual oxidase expression in mud crab. Fish \& Shellfish Immunology 104:252-261. https://doi. org/10.1016/j.fsi.2020.05.049

Zelensky, A. N. and Gready, J. E. 2005. The C-type lectin-like domain superfamily. The FEBS Journal 272(24):61796217. https://doi.org/10.1111/j.1742-4658.2005.05031.x

Zhu, L., Tang, X., Xing, J., Sheng, X., and Zhan, W. 2018. Differential proteome of haemocyte subpopulations responded to white spot syndrome virus infection in Chinese shrimp Fenneropenaeus chinensis. Developmental \& Comparative Immunology 84:82-93. https://doi.org/10.1016/j. dci.2018.02.003 